\title{
A decade of TeachMeet: an Interpretive Phenomenological Analysis of participants' tales of impact
}

\author{
Mags Amond $^{1}$, Keith Johnston ${ }^{1}$, Richard Millwood ${ }^{1}$, Ewan McIntosh ${ }^{2}$ \\ ${ }^{1}$ School of Education, Trinity College Dublin, Ireland, ${ }^{2} \mathrm{Co}$-founder, TeachMeet.
}

\begin{abstract}
TeachMeet is an emerging informal professional development event organised by teachers for teachers, commonly described as an unconference. It is a volunteer-led global phenomenon without any established hierarchy. To celebrate the first ten years of TeachMeet, the founders announced an open call for participants to submit, online, their stories of impact.

The resulting submissions were subjected to an Interpretive Phenomenological Analysis (IPA), capitalizing on the 'double hermeneutic' lens of the experience of researchers whose positionality is that of informed insiders.

Findings revealed the categories in which the lived experiences reported by participants reflected the impacts of TeachMeet: ranging from appreciative description of the event they attended to reflective confessions of lifeenhancing transformation in their personal and professional lives, their classrooms and the wider teaching community.

These finding are examined in the light of how they align with several models of evaluation of teacher learning (Guskey 1998, Kennedy 2005, Kirkpatrick 2006, Desimone 2011, Wenger, Trayner and de Laat 2011), and what they indicate about where evolving TeachMeet communities and networks may be situated in an informal learning landscape.
\end{abstract}

Keywords: TeachMeet, IPA, impact, teacher learning, community, network. 


\section{Introduction}

TeachMeet, founded in 2006, is an unconference form of professional learning event, characterised from the start as "for teachers to share good practice, practical innovations and personal insights in teaching" (Wikipedia, nd); it has been aptly dubbed "guerrilla CPD" (Bennett, 2012). Events adopt the focused informality of Open Space Technology (Owen, 1993). Co-founder McIntosh (2009) speaks of the importance of it being free on two fronts - free speech, and free of cost. Social media tools are harnessed for organisational and promotional purposes, and utilised during the events to connect with those who cannot attend in person. Teachers' online discourse, as collated by Amond et al. (2018, p. 241-242), reports significant numbers who consider TeachMeet to be a community of practice $(\mathrm{CoP})$, a personal learning network (PLN), and a part of their continuing professional development (CPD).

In 2016, in order to celebrate reaching the tenth year of TeachMeet, participants were invited to partake in an open online survey in response to the single question "How has TeachMeet made an impact in your life?". This paper reports on an IPA analysis of these responses and provides commentary on the significance of the findings.

\section{Method}

\subsection{What is Interpretive Phenomenological Analysis (IPA)?}

IPA is a qualitative sensemaking research method which seeks to interpret the lived experience of individuals. It is built on three pillars: phenomenology, hermeneutics, and idiography. IPA aims at "identifying the essential components of a phenomenon" (Pietkiewicz et al., 2012, p. 361), in an interpretive analysis which "retains the voice of the participants" (p. 369). According to Noon (2018, p. 75), "the two complementary commitments of IPA are 'giving voice' and 'making sense"'. Smith et al. characterise the process as the "unfurling of perspectives and meanings" (2012, p. 21).

\subsection{Why IPA was chosen for this analysis}

A researcher's positionality as an insider is acknowledged as important in IPA. Oxley (2016, p. 56) states that the "pre-existing knowledge and preconceptions of the researcher are always brought to the encounter with the phenomenon". This feeds into a double hermeneutic cycle, the value of which according to Smith et al. (2012, p. 21), is that "the phenomenon is hidden within the participants' accounts until interpreted by the researcher's own experience". In this case, the research team is experienced in the world of TeachMeet. Noon $(2018$, p. 80$)$ suggests IPA to be "a particularly useful methodology for researching those whose voices may otherwise go unheard"; TeachMeet is a good fit for this, being an informal event which 
has to date been rarely subject to academic scrutiny. The choice of IPA for analysis of these short stories is suggested in Biggerstaff et al., (2008, p. 9) who advise that "data need not be confined to interviews ... other useful sources are ... personal accounts ... documenting their thoughts and experiences ... returns from questionnaires".

\subsection{How this IPA was carried out}

Survey respondents were asked one open question: "How did TeachMeet make an impact in your world?". This open question aligns with the emphasis within IPA on seeking the lived experience of the individual. The survey was open to any TeachMeet participant who could access it online. A purposive cross-section was not sought, but when we examined the random sample that replied by mapping details onto both Rogers' Theory of Diffusion of Innovations (1962) and the Wenger Trayner de Laat Levels of Participation Theory (2011), a fair cross-section in respect of length and breadth of TeachMeet experience was evident from the responses. The replies $(n .=60)$ were anonymised and subjected to an IPA cycle which involved iterative reading of individual descriptions, taking note of content, language and concepts, then clustering and reflecting on emerging themes in order to write a commentary.

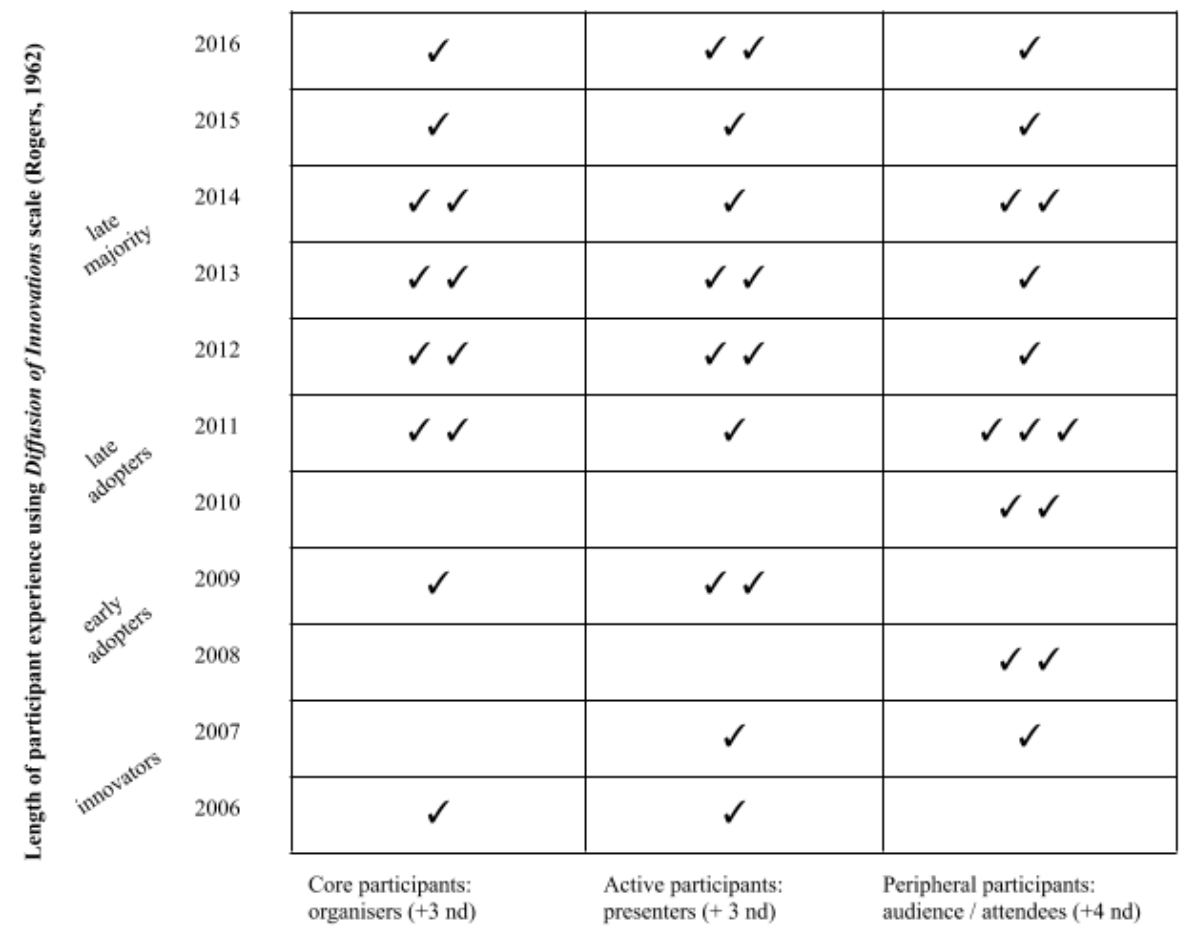

Breadth of participant experience using Levels of Participation scale (Wenger, Treyner, and DeLaat, 2011)

Figure 1. Temporal and experiential profile of survey respondents. 


\section{Findings}

\subsection{Overview of the superordinate themes in the collective narrative}

All of the respondents were educators, with most being currently practicing teachers. Most replies were a paragraph in length, a few were a single sentence, some told longer stories. The question posed asked about "impact in your world". The responses suggested there are ever-widening layers in the worlds of the respondents - their personal world, their classroom world, their professional world and the world of their teaching community.

During analysis, four superordinate categories of comments emerged:

descriptive comments about the event itself;

descriptive comments about the others encountered there;

reflective and narrative comments about the respondent themselves;

reflective and narrative comments about the classroom and the teaching community.

Each superordinate category forks further into subordinate categories; typical quotes for each category are summarised in Table 1.

\subsection{Observations about the TeachMeet event}

These fell into three sub-categories - descriptions of the atmosphere in the venue, the actions of others that were witnessed, and comments on the event organisation. The description of atmosphere was typically of a convivial, open, welcoming space, with repeated instances of 'fun' and 'joy', 'laughter' and 'camaraderie'. The action was that of a packed space, full of conversation, short sharp presentations ( $2 \mathrm{mins}, 7 \mathrm{mins}$ ); lots of mention of Twitter being used; some mentioned being engaged in debate, others mentioned 'lurking'; the overall feel was one of peers sharing their expertise; it was 'teachers talking about teaching'. Remarks about organisation referenced the house rules common to many TeachMeets (a soft toy thrown as a 'time's up' signal, a 'random name picker', 'drinks and nibbles'); many commented on the relaxed and non-hierarchical or 'DIY' nature of the organisation, the fact that is was 'democratic' and the 'opposite to conference guru talks'. 
Table 1. "How did TeachMeet make an impact in your world?" Categories emergent from an IPA of $\mathbf{n}=60$ responses.

\begin{tabular}{|c|c|c|c|c|}
\hline $\begin{array}{l}\text { Superordinate } \\
\text { categories }\end{array}$ & $\begin{array}{l}\text { the event: } \\
\text { comments on the } \\
\text { TeachMeet event } \\
\text { itself }\end{array}$ & $\begin{array}{l}\text { the others: } \\
\text { comments on } \\
\text { the presenters } \\
\text { and audience }\end{array}$ & $\begin{array}{l}\text { the self: } \\
\text { comments on } \\
\text { personal reactions }\end{array}$ & $\begin{array}{l}\text { the } \\
\text { community: } \\
\text { comments on } \\
\text { what happened } \\
\text { afterwards }\end{array}$ \\
\hline $\begin{array}{l}\text { Subordinate } \\
\text { categories }\end{array}$ & $\begin{array}{l}\text { about } \\
\text { atmosphere, } \\
\text { actions, } \\
\text { organisation }\end{array}$ & $\begin{array}{l}\text { about } \\
\text { sharing ideas } \\
\text { inspiration \& } \\
\text { motivation, } \\
\text { participants }\end{array}$ & $\begin{array}{l}\text { about impacts } \\
\text { that were } \\
\text { relational, } \\
\text { emotional, } \\
\text { practical, } \\
\text { transformational }\end{array}$ & $\begin{array}{l}\text { about } \\
\text { transformation } \\
\text { of } \\
\text { personal life, } \\
\text { classroom, } \\
\text { career, } \\
\text { community / } \\
\text { network }\end{array}$ \\
\hline $\begin{array}{l}\text { Typical } \\
\text { comments }\end{array}$ & $\begin{array}{l}\text { on atmosphere } \\
\text { "fun... joy... open } \\
\text { laughter, sharing" } \\
\text { on action } \\
\text { "connecting in real } \\
\text { life... short (7min, } \\
2 \text { min)...everyone } \\
\text { equal... twitter... } \\
\text { debate... eclectic... } \\
\text { the 'in-between" } \\
\text { conversations" } \\
\text { on organisation } \\
\text { "opposite of } \\
\text { conference... } \\
\text { democratic... } \\
\text { without } \\
\text { hierarchy... relaxed } \\
\text { atmosphere... } \\
\text { drinks \& nibbles" }\end{array}$ & $\begin{array}{l}\text { on sharing } \\
\text { "real teachers } \\
\text { sharing real } \\
\text { experiences... } \\
\text { window into } \\
\text { the classroom } \\
\text { of actively } \\
\text { practicing } \\
\text { teachers" } \\
\text { on inspiration } \\
\text { and motivation } \\
\text { "teachers } \\
\text { lighting up } \\
\text { when they talk } \\
\text { about what } \\
\text { they do... } \\
\text { inspiring... } \\
\text { enthusiasm". } \\
\text { on participants } \\
\text { "passionate... } \\
\text { infectious } \\
\text { passion... } \\
\text { authentic... } \\
\text { expressing } \\
\text { beliefs... } \\
\text { positive" }\end{array}$ & $\begin{array}{l}\text { relational } \\
\text { "chance to } \\
\text { network... meet } \\
\text { friends... } \\
\text { exchanging } \\
\text { ideas... } \\
\text { (newcomers) felt } \\
\text { welcomed" } \\
\text { emotional } \\
\text { "inspiration... } \\
\text { enthused... } \\
\text { revitalised... } \\
\text { excited to get } \\
\text { back to classroom } \\
\text { next day" } \\
\text { practical } \\
\text { "most effective } \\
\text { and cheapest } \\
\text { CPD... testing } \\
\text { ideas in the in- } \\
\text { between debates" } \\
\text { transformational } \\
\text { "showed me the } \\
\text { power of } \\
\text { grassroots... the } \\
\text { chance to share is } \\
\text { so powerful" }\end{array}$ & $\begin{array}{l}\text { on personal life } \\
\text { "gave confidence } \\
\text { to be daring... } \\
\text { organised more } \\
\text { teachmeets... } \\
\text { went to more } \\
\text { teachmeets... life- } \\
\text { changing... left } \\
\text { feeling different" } \\
\text { on classroom } \\
\text { "left excited to } \\
\text { share with my } \\
\text { students... } \\
\text { shaped my } \\
\text { teaching... } \\
\text { impacted } \\
\text { practice" } \\
\text { on career } \\
\text { "made me } \\
\text { research a } \\
\text { masters... did } \\
\text { PhD... changed } \\
\text { my professional } \\
\text { life" } \\
\text { on community } \\
\text { "connections... } \\
\text { new network... } \\
\text { building a } \\
\text { community... } \\
\text { doing it ourselves } \\
\text {... on our own" }\end{array}$ \\
\hline
\end{tabular}




\subsection{Observations about others encountered at TeachMeet}

When describing the others encountered and the effect they had on the respondents, three sub-categories of comments emerged - the sharing of practical ideas, inspiration and motivation, and descriptors of the presenters. The sharing of practical ideas was mentioned frequently - practical ideas from other people's classrooms, 'real experiences', 'innovative ideas' modelled by others, and a peek through 'a window into their classroom' were appreciated. The infectious nature of inspiring and motivating presenters was reported many times, their enthusiasm and the unselfish nature of 'teachers lighting up from inside when they talk about what they do'. A remarkable number of responses included the names of the teachers whose presentations made an impact. The stand-out descriptors of others repeated many times in the reports of TeachMeet presenters were that of 'generous', 'passionate', 'positive', 'authentic', 'honest' and 'truly excellent educator[s]'.

\subsection{Observations about the self on attending TeachMeet}

Reports about the effect of attending the TeachMeet address four effects on the self relational, emotional, practical, and transformational. In relational terms, respondents expressed appreciation for meeting others, feeling welcomed, and making friends. On an emotional level, there was much talk of being 'totally inspired', enthused, re-vitalised, excited, 'having a wonderful experience' and 'walking away full of the joys of what we do'. The practical effects listed were about seeing new resources, and having the chance to try them out, 'testing half-baked ideas in the in-between debate'. One comment echoes that often seen posted online after a TeachMeet, calling it 'the most effective and cheapest CPD I have experienced'. Some of the reports were of effects of a potentially transformational nature, of renewal of passion, happiness, and about feelings of empowerment: 'the chance to share what you know is so powerful', 'the power of grassroots'.

\subsection{Observations about wider impact on the teaching community}

Many of those reporting impacts and outcomes after experiencing TeachMeet detailed some lasting transformational effects in one or more of four areas of their lives - their personal life, their classroom life, their teaching career, and their teaching community. Writing of transformational impacts on themselves as a teacher and as a person after encountering TeachMeet, many spoke in terms of being reinvigorated as a teacher, 'changed my view on education', 'a big effect on my learning and my life', 'left the TeachMeet feeling like a different person'. The words 'life changing' appeared several times. The friendships developed were mentioned by many. The most striking change was the number of participants who reported that they went on to attend, present at, and organise TeachMeets. Transformational impacts in the classroom were noted by participants who said they were returning to their classroom with new ideas and a new passion, 'a new zest for teaching', some feeling they had a 'license to try new things', 'explore, be inventive and joyful', 'to 
develop the ideas of others'. All of these developments were reported with reflective honesty ... 'it impacted my practice', 'I may be a better person and more importantly a better educator'. Transformational impact on the career, although not as widely reported as impact on the self, was in some cases quite dramatic - many described a personal and professional growth that lead them to further study, 'I signed up for a Masters', 'it made me research', 'I co-wrote a paper', 'I now lecture at initial teacher training'. Two ensuing $\mathrm{PhD}$ enrolments were mentioned. Some saw it as an 'opportunity to lead', for another it 'helped me at an interview', 'a night that changed my professional life'. Transformational impacts on the wider teaching community is inferred in the many reports of highly appreciated and ongoing new 'connections' 'collaborations', 'networks', 'PLN', 'increased trust and respect', 'building a community'. There was repeated thanking of named and unnamed others. One comment resonates with something that is often posted online by those who attend an unconference for the first time: 'it transformed my attitude to what CPD could be in the hands of teachers'.

\section{Discussion of findings}

Table 1 represents an interpretive reduction and summary of the reports of impact of TeachMeet in the previous years as experienced by 60 respondents from across the globe. Themes ranged from descriptive commentaries on the event and the people involved to reflective, and in many cases, confessional tales of transformation in the personal and professional spheres of their lives.

This progression reflects the stepped layers of success present in many of the classic models and theories of evaluative CPD such as Desimone's Path Model (2011), Guskey's Five Levels model (1998), the Kirkpatrick Four Levels model (2006), the Wenger, Trayner and de Laat Value Creation model (2001). In all of these models modest success is represented by a positive reaction to the event itself, but the highest level of success is represented by a change across the system. Examined in the light of Kennedy's Five Tool framework (2005, p. 247), many of the listed characteristics of success can be detected - "development of the collective as well as the individual, increase in professional autonomy, facilitation of transformation" - rather than mere transmission. Although the sample reflects only educators involved in the TeachMeet community, it suggests that TeachMeet can be benchmarked as a format for informal professional learning.

The articulated appreciation of the networks and communities formed as a result of TeachMeet suggest a cohort seeking the connectivity of a personal learning network as espoused by Siemens (2006) or a community of practice in which they can move from "legitimate peripheral participation" (Lave and Wenger, 1991, p. 27) ) to developing capacity and agency by what one respondent called 'doing it for ourselves'. 


\section{Conclusion}

The interpretive phenomenological analysis of the responses from TeachMeet participants to a call to detail it's impact on 'their world' identified four categories of impact: relating to the event itself; the others encountered there; the person themselves; and the wider classroom and teaching community. Furthermore, this analysis presents evidence, albeit mainly localized and on an individual basis, of the potential and actual value of TeachMeet as an informal peer-organised professional learning activity. We suggest that, as TeachMeet evolves and matures, further data should be generated from a wider and more purposeful sample, using more probing research questions and seeking deeper insights from experienced participants. This would benefit both the TeachMeet community, and the broader professional learning world.

\section{References}

Amond, M., Johnston, K., Millwood, R. (2018). Self-organised Professional Development The TeachMeet Phenomenon. INTED 2018. Proceeding, pp. 239-248.

Bennett, L. (2012). TeachMeets: Guerrilla CPD. SEDA. eprints.hud.ac.uk/id/eprint/16312

Biggerstaff, D. and Thompson, A. R. (2008). Interpretative Phenomenological Analysis (IPA): A Qualitative Methodology of Choice in Healthcare Research. Qualitative Research in Psychology, Vol. 5(3), pp. 214-224

Desimone, L. (2011). A Primer on Effective Professional Development. Phi Delta Kappan 92, no. 6 (March 2011): 68-71.

Guskey, T. (1998). The Age of Our Accountability. Journal of Staff Development 19, no. 4 : 36-44.

Kennedy, A. (2005, 2014). Models of continuing professional development (CPD): a framework for analysis. Professional Development in Education, 40(3), 336-351.

Kirkpatrick, D and Kirkpatrick, J. (2006). Evaluating Training Programs. Oakland: BerrettKoehler, 2006.

McIntosh, E. (2009). TeachMeet09 at BETT is freedom. Blog post available at https://edu.blogs.com/edublogs/2008/12/teachmeet09-at-bett-freedom.html

Lave, J., \& Wenger, E. (1991). Legitimate Peripheral Participation. In Situated Learning: Legitimate Peripheral Participation (Learning in Doing: Social, Cognitive and Computational Perspectives, pp. 27-44). Cambridge: Cambridge University Press

Many authors. Nd. TeachMeet. Wikipedia. https://en.wikipedia.org/wiki/TeachMeet

Noon, E. J. 2018. Interpretive Phenomenological Analysis: Appropriate Methodology for Education Research? Journal of Perspectives in Applied Academic Practice, 6(1), 75-83

Owen, H. (1993). Open Space Technology - A User's Guide. Oakland: Berrett-Koehler.

Oxley, L. (2016). An examination of Interpretative Phenomenological Analysis (IPA). Educational and Child Psychology, 33(3), 55-62

Rogers E. M. (2003). The diffusion of innovations (5th ed.). New York: Free Press. 
Siemens, G. (2005). Learning in the Digital Age. Online paper. Available at http://www.itdl.org/journal/jan_05/article01.htm.

Smith, J.A, Flowers, P., Larking, M. 2012. Interpretive Phenomenological Analysis - Theory, Method and Research. Sage Publications.

PietKiewicz, I., and Smith, J.A. (2012). Praktyczny przewodnik interpretacyjnej analizy fenomenologicznej w badaniach jakościowych w psychologii. Czasopismo Psychologiczne, 18(2), 361-369. In translation.

Wenger, E., Trayner, B., and de Laat, M. (2011). Promoting and assessing value creation in communities and networks: a conceptual framework. http://wenger-trayner.com/ 